\title{
Separation of saline oily wastewater by membrane distillation
}

\author{
Marek Gryta ${ }^{1}$ \\ Received: 24 June 2019 / Accepted: 22 January 2020 / Published online: 30 January 2020 \\ (c) The Author(s) 2020
}

\begin{abstract}
Membrane distillation was used for the treatment of saline oily wastewaters collected from harbour deoiling installation. The turbidity of these wastewaters was in the range 63-87 NTU, salt concentration was 6-11 g/L and the oil content in the feed was below $40 \mathrm{mg} / \mathrm{L}$. Two types of commercial polypropylene capillary membranes were applied for the process study. The intensive membrane fouling during the wastewater separation was observed. Modules rinsed with water removed the organic deposits formed. However, the $\mathrm{CaCO}_{3}$ scale was accumulated on the membrane surfaces during $1500 \mathrm{~h}$ of the process, resulting in a permeate flux decline by more than $40 \%$. The initial yield of modules was recovered by membrane rinsing with $5 \mathrm{wt} \% \mathrm{HCl}$ solution. The long-term studies demonstrated that the separated oily wastewaters did not cause wetting of the applied membrane. The degree of retention amounted to $98 \%$ for the inorganic compounds and more than $99 \%$ for the organic compounds.
\end{abstract}

Keywords Membrane distillation $\cdot$ Oily wastewater $\cdot$ Bilge water $\cdot$ Brine

\section{Introduction}

The global expansion of maritime transport and various technologies (e.g., oil and shale gas production) generate a huge amount of saline wastewaters, which resulted in environmental degradation due to direct discharge of saline wastewater into the environment. The membrane processes can be used most effectively for the treatment of such wastewaters, but one of the major constrains is the durability of membranes, particularly during the separation of brines containing various surface-active contaminants (e.g., oils and surfactants) (Chew et al. 2017; Lu et al. 2018; Rezaeia et al. 2017; Rezaeia et al. 2018, Tanudjaja and Chew 2018).

This work was presented at the 44th International Conference of Slovak Society of Chemical Engineering held in Tatranské Matliare on May 21-25, 2018.

Electronic supplementary material The online version of this article (https://doi.org/10.1007/s11696-020-01071-y) contains supplementary material, which is available to authorized users.

Marek Gryta

marek.gryta@zut.edu.pl

1 Faculty of Chemical Technology and Engineering, West Pomeranian University of Technology in Szczecin, ul. Pułaskiego 10, 70-322 Szczecin, Poland
A high concentration of salts in wastewaters makes their biological purification often impossible and such types of effluents are usually not treated by industrial wastewater treatment plant, which enhances a risk of illegal discharge into the environment. The possibility of water evaporation from high concentration brine enables the application of membrane distillation (MD) for desalination of hypersaline water or the treatment of saline wastewater (Duong et al. 2015; Gryta 2017; Ji et al. 2010; Winter et al. 2017). An integration of MD process with crystallization allows to eliminate the salts discharge (Salmón and Luis 2018). Moreover, the high salt concentration increases the scaling intensity of membranes, which additionally restricts the MD utilization for oily wastewater treatment (Duong et al. 2015; Gryta 2017; McGaughey et al. 2017). However, this process can be very attractive in the case the wastewater treatment by conventional methods is difficult or very expensive, especially for oily wastewaters such as bilge water (ships) or wastewater generated in the process of hydraulic fracturing (natural gas extraction) (Chew et al. 2017; Gryta et al. 2001; Lu et al. 2018; Tavakkoli et al. 2017).

The porous non-wetted hydrophobic membranes are used in the membrane distillation (Gryta 2017; Wang and Chung 2015; Winter et al. 2017). However, the hydrophobic membranes are intrinsically prone to fouling by hydrophobic contaminants due to the strong 
hydrophobic-hydrophobic interaction (Chew et al. 2017; Lin et al. 2014; Rácz et al. 2015; Rezaeia et al. 2017). Therefore, the conventional hydrophobic membranes (made of PP, PTFE and PVDF) are usually applied for desalination of water when the hydrophobic contaminants concentration is relatively low (Gryta 2017; Guillén-Burrieza et al. 2011; Winter et al. 2017). A progressive wetting of hydrophobic membrane is observed even for clean water, such as seawater, which is attempted to be eliminated by the application of superhydrophobic membranes (Guo et al. 2015; Hamzah and Leo 2017; Lin et al. 2014; McGaughey et al. 2017; Rezaeia et al. 2017). However, a very low surface energy of these membranes accelerates the membrane wetting when the hydrophobic contaminants will be present in the feed water. Therefore, the new composite hydrophilic/hydrophobic membranes or membranes with amphiphobic surfaces were proposed for desalination of this type of feed (Guo et al. 2015; Hou et al. 2018; Lin et al. 2014, 2015; Mostafa et al. 2017; Rezaeia et al. 2017). Unfortunately, the relatively high costs of proposed new membranes are expected to be problematic, because the industrial breakthrough of the contactors technology requires a high performance and inexpensive membranes (Eykens et al. 2017, 2018).

In this work, the relatively inexpensive polypropylene (PP) membranes (Macedonio et al. 2014; Wang and Chung 2015) were used for evaluation of the membrane stability during MD process applied for the separation of actual oily wastewaters. The capillary PP membranes were not wetted during the separation of bilge water (Gryta and Karakulski 1999; Gryta et al. 2001) and oilfield produced water (Macedonio et al. 2014). The major reason of pores wetting is the precipitation of different inorganic scales (scaling) besides the oil adsorption on the membrane surface. A promising method reported to mitigate the fouling and scaling intensity is the application of low feed temperature (Duong et al. 2015); however, such an option reduces the effectiveness of processes realized in the membrane contactors. Therefore, a larger membrane area should be used to achieve a high efficiency of the MD installation, which increases the capital investment costs (Tavakkoli et al. 2017). This is an additional reason indicating that the realization of industrial implementation requires the MD membranes to be as cheap as possible, namely, manufactured by a simple method from inexpensive raw materials (Eykens et al. 2018; Rezaei et al. 2018).

The membrane degradation processes have a slow progress (Gryta 2018; McGaughey et al. 2017); therefore the continuous long-term studies, presented in this work, are required to determine their influence on the PP membrane performance during the separation of oily wastewaters.

\section{Experimental}

The hydrophobic capillary polypropylene membranes (Accurel PP), manufactured for microfiltration process by Membrana GmbH (Germany), were applied to carry out the MD experiments. The nominal diameter of the membrane pores was $0.2 \mu \mathrm{m}$ and the porosity was $73 \%$ (supplier data). The thickness of membrane wall has a significant effect on the MD process performance (Gryta 2017). Therefore, two types of the capillary membranes with different diameters were used for comparison purpose. The membrane Accurel PP S6/2 has the inner diameter equal to $1.8 \mathrm{~mm}$ and wall thickness $0.4 \mathrm{~mm}$. The wall thickness was about four times larger for Accurel PP V8/2 HF membrane $\left(d_{\text {in }} / d_{\text {out }}=5.5 / 8.6 \mathrm{~mm}\right)$.

Two submerged modules (SMD1 and SMD2) made from Accurel PP membranes were placed in the glass feed tank ( $4 \mathrm{~L}$ ), which enabled both membrane types to be tested simultaneously under similar conditions (e.g. feed composition). The feed tank was located on a magnetic stirrer equipped with a heating element (600 W, IKA, USA). During the separation of actual oily wastewaters, the feed temperature equal to $323 \mathrm{~K}$ was used. A design of the experimental setup used is shown in the Supplementary Material (Fig. S1). The SMD1 module was assembled using four Accurel PP S6/2 membranes with the length of $20 \mathrm{~cm}$ (inside area $45 \mathrm{~cm}^{2}$ ). The SMD2 module was composed of a single membrane Accurel PP V8/2 HF with the length of $25 \mathrm{~cm}$ (inside area $34.5 \mathrm{~cm}^{2}$ ). Each of the submerged modules was connected to an individual distillate tank, cooled in the water bath (290-293 K). The initial volume of distilled water in the distillate tanks amounted to $1.0 \mathrm{~L}$. The peristaltic pumps were used to obtain the volumetric flow rate of distillate (inside capillary membrane) equal to $6 \pm 0.2 \mathrm{~mL} / \mathrm{s}$ (linear velocity of $0.59 \mathrm{~m} / \mathrm{s}-\mathrm{SMD} 1$ module and $0.79 \mathrm{~m} / \mathrm{s}-\mathrm{SMD} 2$ module).

The studies were performed with samples of wastewaters collected from harbour deoiling installation at intervals of a few days. The tested samples were light to dark brown in colour and they exhibited a high turbidity. The composition of oily wastewaters is presented in Table 1 .

The MD process was carried out in a continuous mode (day and night), while a new portion of wastewater was periodically added into the feed tank. At the initial stage, the efficiency of MD modules was tested using $\mathrm{NaCl}$ solution $(5 \mathrm{~g} / \mathrm{L})$ and the feed temperature in the range 308-333 K.

The solutions compositions (anion and cation concentrations) were determined using an ion chromatography method with conductivity detector (850 Professional IC, Herisau Metrohm, Switherland). The analytical columns Metrohm A Supp5-250 and Metrosep C2-150 were 
Table 1 The composition of tested oily wastewaters

\begin{tabular}{|c|c|c|c|c|c|c|c|c|c|c|c|c|c|}
\hline \multirow[t]{2}{*}{ Waste } & \multicolumn{9}{|c|}{ Ions [mg/L] } & \multirow[t]{2}{*}{ Oil (mg/L) } & \multirow[t]{2}{*}{$\mathrm{pH}$} & \multirow[t]{2}{*}{ NTU } & \multirow[t]{2}{*}{$\mathrm{SS}^{*}(\mathrm{~g} / \mathrm{L})$} \\
\hline & $\mathrm{Cl}-$ & $\mathrm{Br}-$ & $\mathrm{NO}_{3}{ }^{-}$ & $\mathrm{SO}_{4} 2-$ & $\mathrm{Na}+$ & $\mathrm{NH}_{4}+$ & $\mathrm{K}+$ & $\mathrm{Ca} 2+$ & $\mathrm{Mg} 2+$ & & & & \\
\hline OW1 & 5238 & 130 & 96 & 705 & 3356 & 25 & 142 & 1034 & 645 & 12.5 & 8.5 & 87.3 & 0.57 \\
\hline OW2 & 3383 & 128 & 59 & 876 & 1969 & 62 & 115 & 494 & 420 & 24.8 & 8.6 & 64.3 & 0.38 \\
\hline
\end{tabular}

$\mathrm{SS}^{*}$ suspended solids

applied for analysis of cations and anions, respectively. A 6P Ultrameter (Myron L Company, USA) multimeter was applied for measurement of solution electrical conductivity.

The surface tension of liquid and the membrane contact angle significantly affect the membrane wettability. The measurements of these parameters were performed using an apparatus Sigma 701 microbalance (KSV Instrument, Ltd., Finland) applying the Wilhelmy plate method.

The examination of membrane morphology and the scaling layer composition was performed using a Hitachi su8000 field emission scanning electron microscope (FESEM) with energy-dispersive X-ray spectrometer (EDS). The membranes for the cross-sectional observation were prepared by fracture of the capillary in liquid nitrogen.

The oil concentration in the solutions was analysed using OCMA 310 apparatus (Horiba, Japan). In addition, the content of organic compounds in the wastewaters was determined on the basis of analyses of the total organic carbon (TOC-Analyzer multi N/C, Analytic Jena).

\section{Results and discussion}

\section{MD process efficiency}

The MD process was carried out below the boiling point of water that enables the utilization of low-grade heat sources of energy. The feed temperature is usually in the range of 313-333 K, e.g., when solar collectors are applied as an energy source (Schwantes et al. 2013; Wang and Chung 2015). The efficiency of SMD1 and SMD2 modules for these feed temperatures is presented in Fig. 1.

The vapour partial pressure (driving force in MD) increases exponentially with temperature, thus the highest permeate flux was obtained for $333 \mathrm{~K}$ (Fig. 1). However, the application of lower feed temperature allows to significantly limit the membrane scaling (Duong et al. 2015; Gryta 2017; Rezaeia et al. 2017). Because the feed temperature decreases rapidly during the feed flow in the MD module, the small yields can be expected for temperature below $318 \mathrm{~K}$. For this reason, the efficiency of spiral-wound MD modules, even for higher feed inlet temperature (e.g., $333 \mathrm{~K}$ ), is at a level of $1-3 \mathrm{~L} / \mathrm{m}^{2} \mathrm{~h}$ in the pilot plant installations (Hagedorn et al.

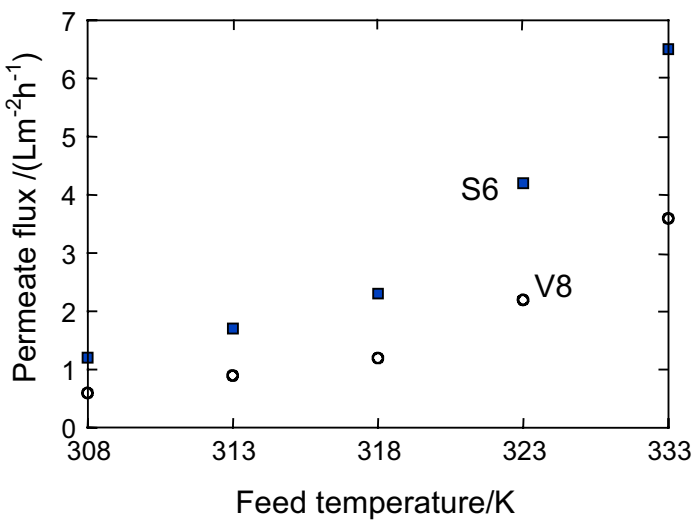

Fig. 1 The influence of feed temperature on the permeate flux for Accurel PP S6/2 (filled square) and Accurel PP V8/2 HF membranes (open circle). Feed: $5 \mathrm{~g} \mathrm{NaCl} / \mathrm{L}$

2017). The results presented in Fig. 1 indicated that a solution of this problem might be the application of submerged modules with the capillary membranes assembled inside the feed tank. In this case, the entire surface of the capillaries is in contact with the feed at the same temperature. As a result, 2-3 times larger efficiency than those presented for spiral-wound modules was achieved at the feed temperature of $323 \mathrm{~K}$ (Fig. 1). An additional advantage of using the submerged modules is a lack of forcing pressure of the feed, which should restrict the penetration of liquid into the pores (membrane wetting).

Although the membranes with thicker walls exhibited a greater resistance to wetting and degradation (Gryta 2017), a significantly lower yield was obtained for such membranes due to the increase in mass transfer resistance. The Accurel PP V8/2 HF membrane has four times thicker walls $(1.5 \mathrm{~mm})$ in comparison to the membranes Accurel PP S6/2 $(0.4 \mathrm{~mm})$. However, the increase of wall thickness not only extends the diffusion path of vapour, but also favourable limits the heat losses through the membrane (temperature polarization). In this regard, the permeate fluxes obtained for the Accurel PP V8/2 HF membranes were only two times lower than those obtained for Accurel PP S6/2 (Fig. 1). The efficiency tests of SMD1 and SMD2 modules lasted about $30 \mathrm{~h}$ and the electrical conductivity of distillates were at a level of $2-3 \mu \mathrm{S} / \mathrm{cm}$ during this period. In the next stage 
of MD studies, the modules were supplied by saline oily wastewaters for nearly $1500 \mathrm{~h}$, which may cause a partial wetting of the membranes resulting in the deterioration of obtained distillate.

\section{Separation of oily wastewaters}

The resistance of membranes to wetting is dependent in a large degree on the hydrophobicity of the membranes and the surface tension of the solutions to be separated. The measurements performed by the Willhelmy plate method indicated that for the membranes used, the similar values of the contact angle of the outer capillary surface were determined: $99^{\circ} \pm 3^{\circ}$ for Accurel PP S6/2 and $98^{\circ} \pm 2^{\circ}$ for Accurel PP V8/2 HF. The surface tension of oily wastewaters was $42.3 \mathrm{mN} / \mathrm{m}$ and $39.8 \mathrm{mN} / \mathrm{m}$ for OW1 and OW2 samples (Table 1), respectively. These values are higher than the PP surface tension-30 $\mathrm{mN} / \mathrm{m}$ (Nieto et al. 2012), hence, the treated wastewaters should not wet the applied Accurel PP membranes. The electrical conductivity of wastewaters was $8.13 \mathrm{mS} / \mathrm{cm}$ (OW1) and $5.13 \mathrm{mS} / \mathrm{cm}$ (OW2), therefore, a rapid increase in the distillate conductivity will be observed in the case of wetting of even a small fragment of the membrane wall.

The feeding of MD modules with actual oily wastewater (OW1) caused a decline of permeate flux from $3 \mathrm{~L} / \mathrm{m}^{2} \mathrm{~h}(\mathrm{~S} 6)$ and $1.8 \mathrm{~L} / \mathrm{m}^{2} \mathrm{~h}(\mathrm{~V} 8)$ to a level of 2 and $1 \mathrm{~L} / \mathrm{m}^{2} \mathrm{~h}$, respectively, during the initial $500 \mathrm{~h}$ of MD process carried out at $323 \mathrm{~K}$ (Fig. 2). In the case of MD process, a reason of such flux decline is most often associated with the wetting of the surface pores and membrane fouling (Gryta 2017; McGaughey et al. 2017). Moreover, a rapid increase in the

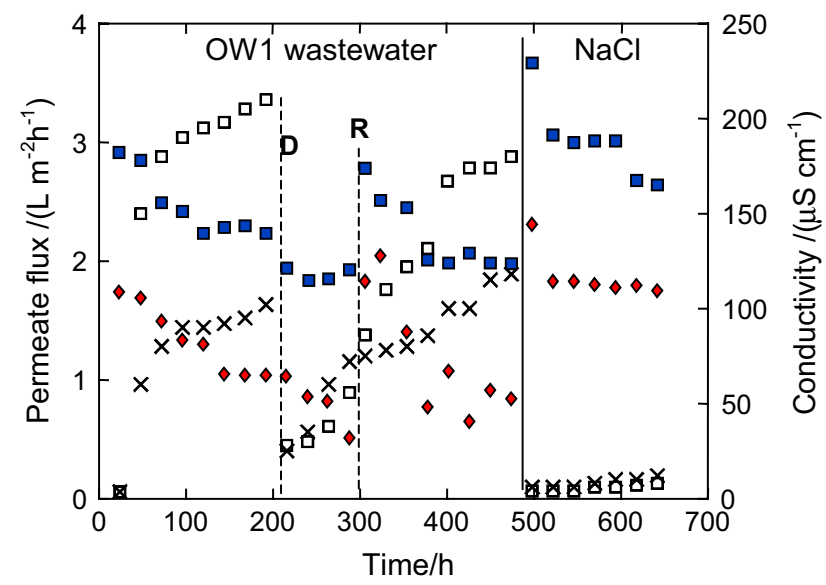

Fig. 2 The changes of the permeate flux (filled square and diamond) and distillate electrical conductivity (open square, $\times$ ) during treatment of oily wastewater by MD process. Membranes: open and filled square: Accurel PP S6/2; filled diamond and $\times$ : Accurel PP V8/2 HF. $R$ modules rinsed with water, $D$ distillate side was re-filled with a new portion of distilled water. Feed temperature $323 \mathrm{~K}$ distillate conductivity to a value of $220 \mu \mathrm{S} / \mathrm{cm}$ (S6) and 130 $\mu \mathrm{S} / \mathrm{cm}(\mathrm{V} 8)$ can be a confirmation of the aforementioned phenomena, since the fouling/scaling is often a reason of the membrane wetting in the MD process (Rezaei et al. 2018). The wetting of some pores in the membrane wall enables non-volatile salts to diffuse from the feed into the distillate, resulting in an increase of distillate conductivity (Gryta 2017; Ji et al. 2010). However, when the $\mathrm{NaCl}$ solution $(5 \mathrm{~g} / \mathrm{L})$ was again used as a feed, after $500 \mathrm{~h}$ of MD process operation, the distillate conductivity was reduced to a level of $10-15 \mu \mathrm{S} / \mathrm{cm}$, and the permeate flux increased to almost the initial values (Fig. 2, period 490-650 h). Such results indicate that the treated OW1 oily wastewater did not cause the membrane wetting and the changes of process parameters shown in Fig. 2 resulted from other reasons. The observed decrease of MD efficiency during the separation of OW1 wastewater most probably resulted from the membrane fouling, which will be discussed in the next paragraph.

The $\mathrm{pH}$ value of used OW1 wastewater amounted to 8.5 and the presence of the $\mathrm{NH}_{4}{ }^{+}$ions was found (Table 1). The IC analysis confirmed that a growth of distillate conductivity resulted, among others, from dissolution of ammonia separated from the feed in the distillate. The MD investigations were carried out maintaining a relative constant volume of wastewaters in the feed tank (4 L). However, despite a continuous concentration of the feed and a periodical addition of fresh portion of OW1 wastewater (Fig. 3, VCR points), the $\mathrm{pH}$ values of the feed were systematically decreased, that confirmed the separation of ammonia from the feed. A continuous evolution of ammonia from the feed caused the distillate conductivity to again increase rapidly despite the exchange of water in the distillate cycle (Fig. 2, point D, $210 \mathrm{~h}$ ). After about $290 \mathrm{~h}$ of the MD process, the module

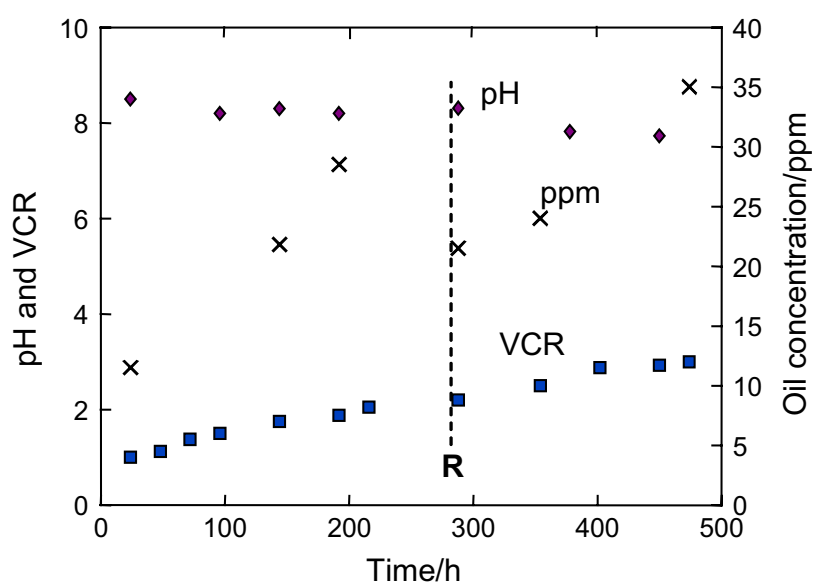

Fig. 3 The changes of $\mathrm{pH}$ (filled diamond) and oil content $(x)$ in the feed, and the obtained values of VCR (filled square) during separation of OW1 wastewater. Point R: module and feed side of MD installation rinsed with water. Feed temperature $323 \mathrm{~K}$ 
and installation were washed with water, followed by filling of the feed tank with concentrated solution (MD retentate). An analysis of the oil content in the feed showed that this operation caused a decrease in oil concentration, which is associated with the oil adsorption on the surface of the clean walls of the installation.

The results shown in Fig. 4 indicate that an increase of the membrane thickness limits the separation of ammonia, since the concentration of $\mathrm{NH}_{4}{ }^{+}$ions was twofold higher in the distillate obtained for Accurel PP S6/2 membranes. Moreover, the concentration of other ions such as $\mathrm{Cl}^{-}$and $\mathrm{Na}^{+}$was also lower. Such results confirmed that the Accurel PP V8/2 HF membranes having a significantly thicker membrane wall were also more resistant for wetting (Gryta 2017). The OW1 wastewater was concentrated three times more during the performed studies, which allowed to obtain the water recovery equal to $66 \%$. The final salt concentration in the feed exceeded $30 \mathrm{~g} / \mathrm{L}$, hence, for the ionic concentration in the distillate at a level of 10-20 mg/L (Fig. 4), a salt retention coefficient close to $99.8 \%$ and $99.9 \%$ was maintained for Accurel PP S6/2 and Accurel PP V8/2 HF membranes, respectively.

In the second stage of MD investigations the OW2 oily wastewater was used. This wastewater contained almost two times less salts, but the content of oil contaminations was higher (Table 1). The MD process efficiency obtained for such wastewater is shown in Fig. 5. The obtained permeate flux decreased from 2.6 to $1.4 \mathrm{~L} / \mathrm{m}^{2} \mathrm{~h}$ (S6 membranes) and from 1.9 to $0.6 \mathrm{~L} / \mathrm{m}^{2} \mathrm{~h}$ for $\mathrm{V} 8$ membranes during the first $180 \mathrm{~h}$ of the treatment of OW2 wastewater by MD. A decline of the permeate flux was similar to that observed during the OW1 wastewater separation, which indicates that the increase in oil concentration did not have a major

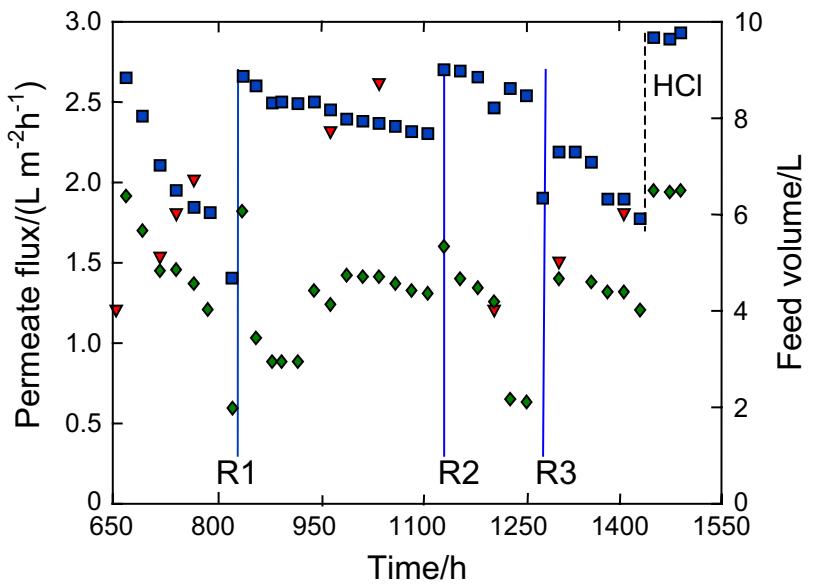

Fig. 5 The changes of the permeate flux (filled square: S6, filled diamond: V8) and the total volume of OW2 wastewater (filled triangle) dosed into feed tank during MD process of oily wastewater. R1-R3: modules rinsed with water

impact on the MD process (in the tested range $12-40 \mathrm{mg} / \mathrm{L}$ ). However, the permeate flux increased, when the SMD1 and SMD2 modules were rinsed with water as in the case of OW1 wastewater. This result indicated that the formation of deposit on the membrane surfaces had a significant influence on the yield of used MD modules.

The OW2 wastewater, similarly as OW1 wastewater, also contained the $\mathrm{NH}_{4}{ }^{+}$ions and the $\mathrm{pH}$ of OW2 wastewater was equal to 8.2, which enables the evolution of ammonia from feed to distillate. The IC studies confirmed that significant amounts of the $\mathrm{NH}_{4}{ }^{+}$ions were detected in the obtained distillate, which caused an increase in the electrical conductivity of produced distillate (Fig. 6).

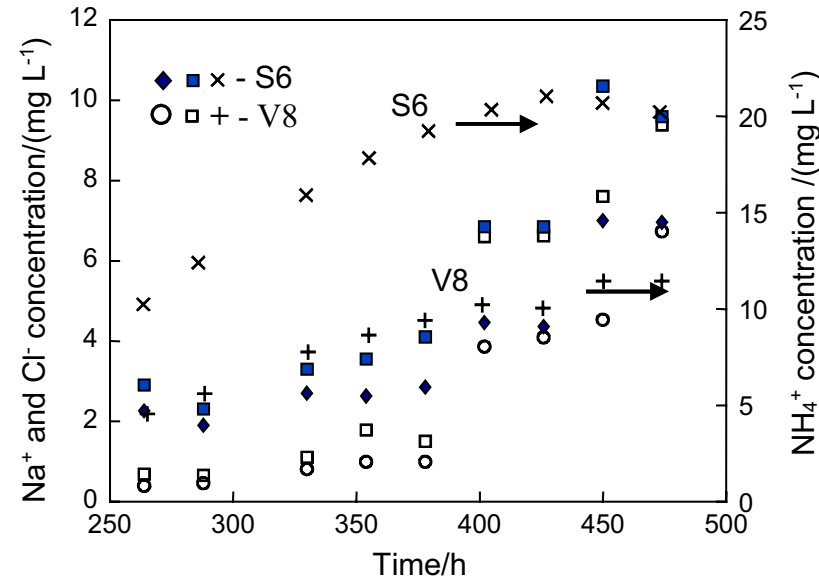

Fig. 4 The changes of ions concentration in distillate during MD process of OW2 wastewater. Feed temperature 323 K. Points: filled and open square: $\mathrm{Cl}^{-}$; filled diamond and open circle: $\mathrm{Na}^{+} ; \times$and + : $\mathrm{NH}_{4}^{+}$

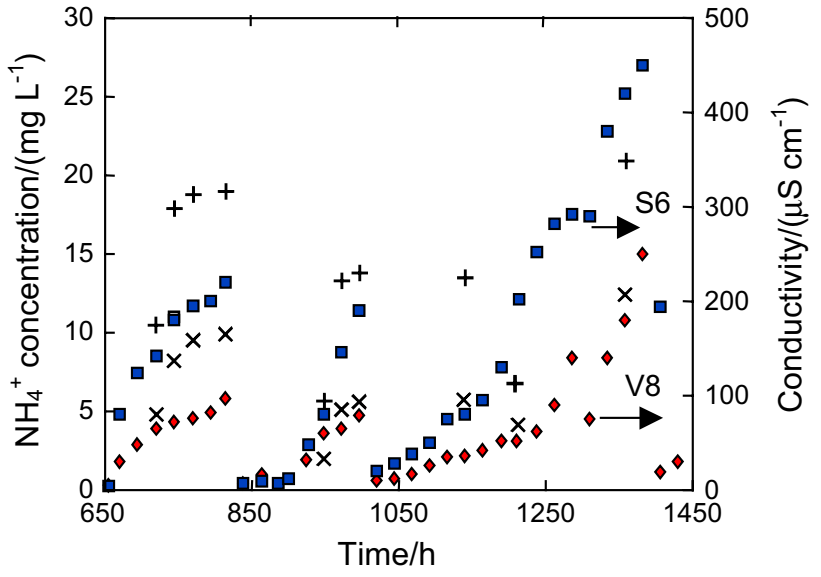

Fig. 6 The changes of $\mathrm{NH}_{4}{ }^{+}$concentration (+: $\mathrm{S} 6, \mathrm{x}$ : V8) in distillate and its electrical conductivity (filled square: S6, filled diamond: V8) during MD process of OW2 wastewater 
When the OW2 wastewater was used in the MD process, similarly as in the case of OW1 wastewater definitely larger values of tested parameters were found for the Accurel PP S6/2 membranes, e.g., a higher concentration of other ions such as $\mathrm{Na}^{+}$and $\mathrm{Ca}^{2+}$ was also determined for these membranes (Fig. 7). Such results confirmed that the membranes with thicker walls (Accurel PP V8/2 HF) exhibited a higher resistance to wetting during the separation of tested saline oily wastewater.

After $550 \mathrm{~h}$ separation of OW2 wastewater, the resulted retentate was replaced by a new portion of OW2 wastewater (Fig. 5, point $1200 \mathrm{~h}$ ). The concentration of ions in the distillate and its electrical conductivity were significantly increased during the MD of the second portion of OW2 wastewater (Figs. 6 and 7, from 1240 h). This may indicate that the pore wetting was systematically increased (but in small degree) during the studies carried out for $1500 \mathrm{~h}$. A confirmation of this conclusion is a fact that the ions concentration in the distillate obtained after $650 \mathrm{~h}$ of separation of OW1 wastewater (Fig. 4) was two times smaller than that obtained for OW2 wastewater (Fig. 7), although the OW2 wastewater contained significantly less salts (Table 1). However, taking into account that the feed electrical conductivity amounted to $35-40 \mathrm{mS} / \mathrm{cm}$, the obtained degree of solutes retention was 98.7\% (Accurel PP S6/2) and 99.3\% (Accurel PP V8/2 HF), although the distillate conductivity was in the order of $250-500 \mu \mathrm{S} / \mathrm{cm}$ (Fig. 6).

The determination of oil content in the obtained distillate indicated for the complete retention of oil in the feed. The sensitivity of applied apparatus OCMA 310 amounts $0.2 \mathrm{mg} / \mathrm{L}$. A good separation of organic compounds was also confirmed by performed studies of the TOC content in the distillate. The concentration of total organic carbon (TOC) in the tested samples varied in the range of $1-2 \mathrm{mg} / \mathrm{L}$,

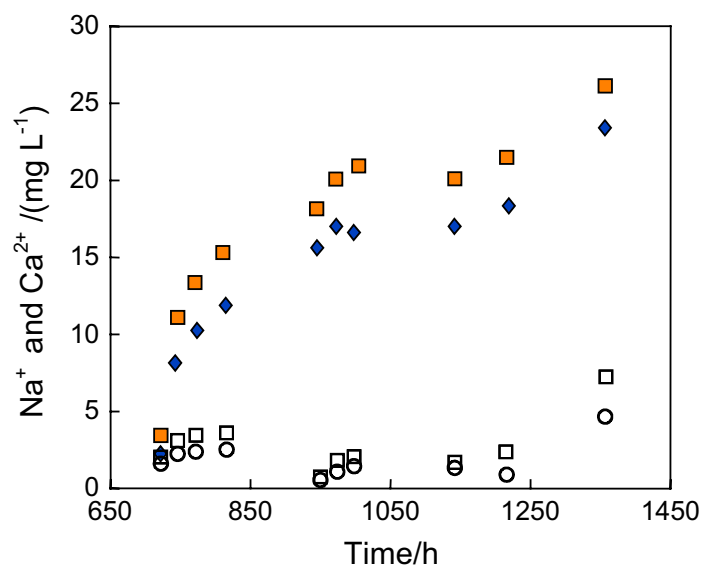

Fig. 7 The changes of ions concentration in distillate during MD process of oily OW2 wastewater. Membranes: S6 (filled square: $\mathrm{Cl}^{-}$, filled diamond: $\mathrm{Na}^{+}$) and V8 (open square: $\mathrm{Cl}^{-}$, open circle: $\mathrm{Na}^{+}$) when the TOC content in the feed was more than $450 \mathrm{mg} / \mathrm{L}$ (retention over 99\%).

\section{Membrane fouling}

The walls of feed tank made of glass allowed to observe the formation of brown deposit accumulated on the membrane surfaces, which indicated that a decrease of the permeate flux (Figs. 3, 5) could be associated with fouling. The oil present in the treated saline wastewaters is one of the components leading to the fouling (Hou et al. 2018; Macedonio et al. 2014). The water evaporation causes the increase in the oil concentration at the feed/membrane interface, which limits the access of water to the membrane surface. As a result, the concentration of oily emulsions in the MD process is limited, since the efficiency of MD process approaches zero at the emulsion concentration of the order 1000 ppm (Gryta and Karakulski 1999). However, the emulsion containing such a large amount of oil undergo breaking, which allows to separate the free oil in an additional device, e.g. skimmer, connected to the MD installation.

In the studied case, treated wastewaters OW1 and OW2 contained initially a small amount of oily substances $(12-25 \mathrm{mg} / \mathrm{L})$. Due to a continuous water evaporation during the MD process the oil concentration in the feed was systematically growing, that enhances a negative effect of the oil presence, although its concentration was still relatively low (30-40 mg/L) (Fig. 3). For this reason, the oil concentration was not the main factor causing the membrane fouling.

The SEM examination confirmed that during MD process the surface of membranes was covered by deposit. Compared to the image of a new membrane (Fig. 8a), it can be concluded that the sediment covered almost the entire surface of the membrane after $300 \mathrm{~h}$ of separation of OW1 wastewater (Fig. 8b). The SEM examination of membrane cross-section revealed that the deposit thickness was small, of the order of 1-5 $\mu \mathrm{m}$ (Fig. 8c). In addition, many pores were visible in the deposit layer, which allowed the feed to flow to the membrane surface, and the SMD1 module performance was reduced by only $40 \%$ despite intensive fouling. Using a high magnification ( $50 \mathrm{k})$, it was found that the sediment contained several spherical forms with size less than $1 \mu \mathrm{m}$ (Fig. 8d). A SEM-EDS analysis revealed that the spherical forms contained a significant amount of $\mathrm{Ca}, \mathrm{O}$ and $\mathrm{C}$, which confirms the formation of $\mathrm{CaCO}_{3}$ deposit.

After $300 \mathrm{~h}$ of investigations, the membranes were rinsed with tap water, and the majority of deposit was removed from the membrane surface. As a result, the SMD1 and SMD2 modules productivity increased to the initial level (Fig. 2, points from $310 \mathrm{~h}$ ). However, the membranes were again covered by deposit after consecutive $50 \mathrm{~h}$ of process and their efficiency was stabilized at a level of $2 \mathrm{~L} /$ $\mathrm{m}^{2} \mathrm{~h}(\mathrm{~S} 6 / 2)$ and $0.9 \mathrm{~L} / \mathrm{m}^{2} \mathrm{~h}$ for the V8/2 HF membranes. The 
Fig. 8 SEM images of Accurel PP V8/2 HF new membrane (a) and membrane after $300 \mathrm{~h}$ separation of OW1 wastewater: $\mathbf{b}$ membrane surface; $\mathbf{c}$ membrane cross-section with deposit, $\mathbf{d}$ deposit: magnification $50,000 \times$ (a)

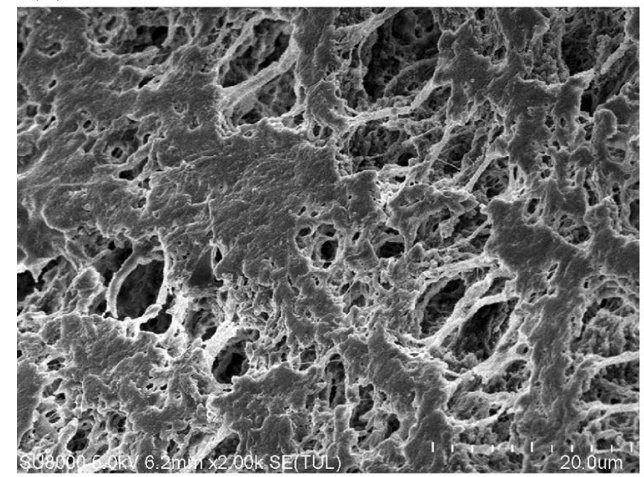

(c)

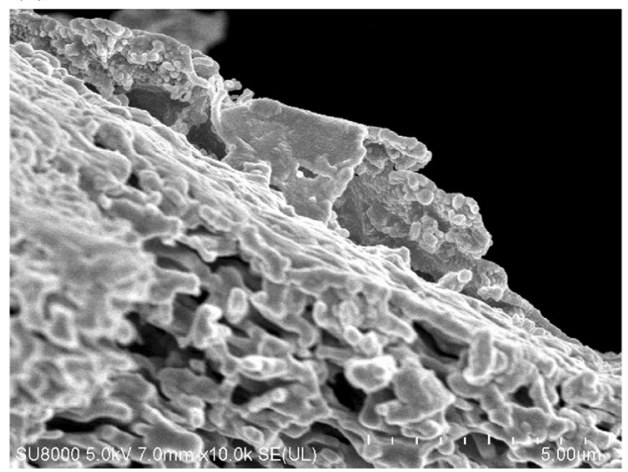

(b)

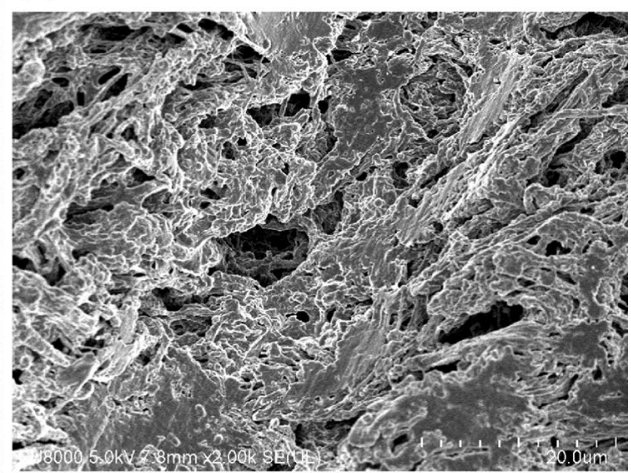

(d)

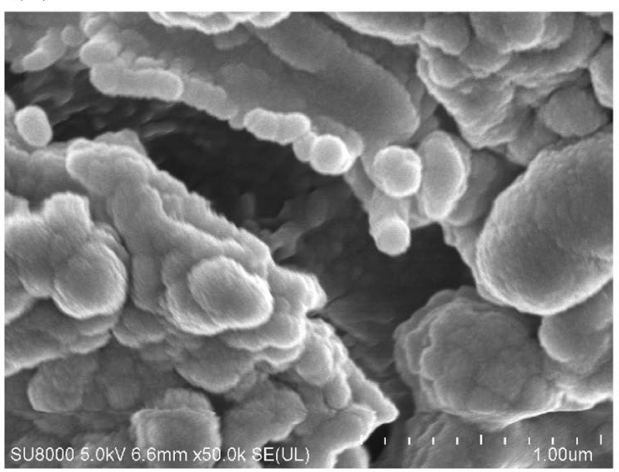

efficiency increased once again after the change of the feed (concentrated OW1) into $\mathrm{NaCl}$ solution (Fig. 2, from $450 \mathrm{~h}$ ), which mainly resulted from a fact, that the membranes were again washed by this kind of feed.

Similarly as in the case of OW1 wastewater, the feeding of modules with OW2 wastewater caused the occurrence of the membrane fouling resulting in a decline of the process efficiency (Fig. 5). After obtaining a 50\% concentration of OW2 wastewater (Fig. 5, from 790 h), the intensity of deposit precipitation was significantly increased. Moreover, a layer of brown deposit was also formed on the feed tank walls. An IC analysis of the feed composition revealed that the concentration of the determined ions was progressively increased. Slight changes were found for the $\mathrm{Ca}^{2+}$ concentration, which was associated with the $\mathrm{CaCO}_{3}$ precipitation. An increase in the intensity of deposit precipitation caused a greater decline of the permeate flux (Fig. 5, $830 \mathrm{~h}$ ). The rinsing of membranes with distilled water allowed to remove the majority of deposits from the membrane surface and the process efficiency was restored to almost the initial values (Fig. 5, point R1). The SEM examinations showed that numerous agglomerates (size 50-100 $\mu \mathrm{m}$ ) remained on the membranes surface after washing the MD modules with water (Fig. 9a). SEM-EDS analysis revealed that the agglomerates consisted mainly of $\mathrm{CaCO}_{3}$ which formed crystals with aragonite- and vaterite-specific shapes, as can be seen in Fig. 9b (Beck and Andreassen 2010; Elfil and Roques 2004). Similarly, the $\mathrm{CaCO}_{3}$ crystal mixture of aragonite and vaterite was found when the $\mathrm{CaCO}_{3}$ was precipitated in water-oil system contaminated by surfactants (Szcześ 2009).

After a further continuation of MD process, the process efficiency was again gradually decreased during the consecutive $180 \mathrm{~h}$, although this decline of the permeate flux was definitely slower, e.g., from 2.68 to $2.3 \mathrm{~L} / \mathrm{m}^{2} \mathrm{~h}(\mathrm{~S} 6 / 2)$. A similarly slower decline of the process efficiency was observed after performing the second cleaning of modules (Fig. 5, point R2).

The results presented in Fig. 5 indicate, that not only the process time and the degree of feed concentration, but also a volume of fresh wastewater added to the feed had influence on the fouling intensity. The initial volume of feed amounted to $4 \mathrm{~L}$, and the permeate volume obtained during $24 \mathrm{~h}$ of MD process amounted to $0.4-0.6 \mathrm{~L}$. The losses of feed volume were periodically supplemented by adding OW2 wastewater (Fig. 5, points $\mathrm{V}_{\mathrm{F}}$ ). The largest decline of efficiency was noted at the initial period, when a large volume of wastewater $(4 \mathrm{~L})$ was heated to $323 \mathrm{~K}$. A periodical dosage of smaller volumes of wastewater OW2 to thermally stabilized feed did not cause a significant reduction of the permeate flux. A similar effect (larger flux decrease) was observed when the concentrated feed was removed from installation and was exchanged by a new portion of wastewater (4L) (Fig. 5, from $1214 \mathrm{~h}$ ). The applied periodic addition of OW2 wastewater caused the layers of deposit growth can be distinguished in the sediment structure (Fig. 9c). Such a result indicates that 
Fig. 9 SEM images of Accurel PP V8/2 HF with deposit formed during separation of OW1 wastewater: a membrane surface; b deposit: magnification 20,000x, c membrane cross-section with deposit (a)

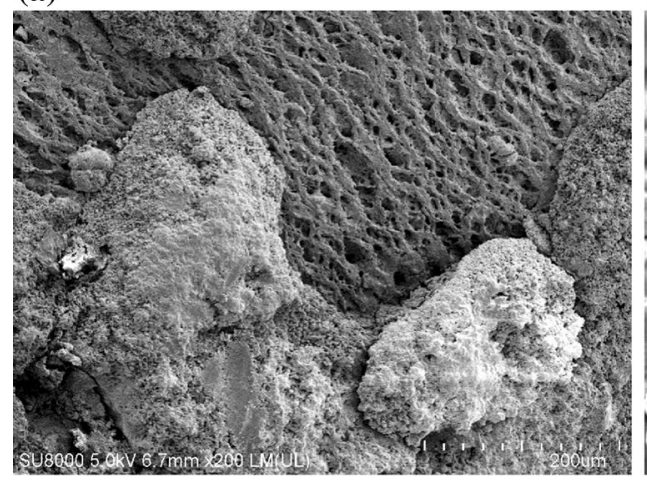

(b)

(c)

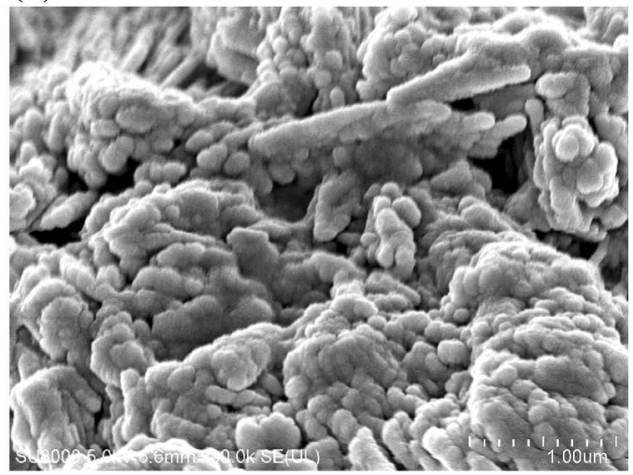

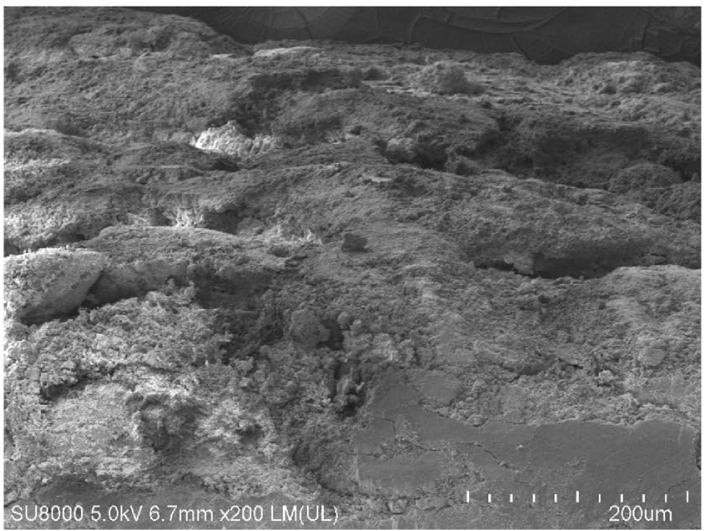

the application of thermal pre-treatment of tested wastewaters could cause a decline of the membrane fouling intensity during MD process.

The obtained results demonstrated that the formation of a significant amount of the sludge deposit on the membrane surfaces takes place during oily wastewater separation by MD process. The majority of sludge can be removed using a cyclic rinsing of the modules with water. However, the effectiveness of washing procedure was reduced (Fig. 5, points R1-R3), due to the occurrence of the membrane scaling besides the formation of organic deposit. The accumulation of $\mathrm{CaCO}_{3}$ scaling layer (Fig. 9c) caused a decline of the permeate flux by more than $40 \%$. A rinsing of the membranes with $\mathrm{HCl}$ solution is a good solution in the case of $\mathrm{CaCO}_{3}$ scaling. The application of $5 \mathrm{wt} \%$ acid solution allowed to clean the membrane surfaces in a few minutes, and as a result, the permeate flux was increased to almost the initial values (Fig. 5, from $1450 \mathrm{~h}$ ).

\section{Conclusions}

The performed studies demonstrated that the MD process can be used for the treatment of saline oily wastewaters. The obtained degree of retention amounted to $98 \%$ for the inorganic compounds and more than $99 \%$ for the organic compounds.

It was confirmed that the membrane wall thickness has a significant effect on the MD process performance. A much better quality of the distillate was obtained for Accurel PP V8/2 HF membrane, which had four times thicker walls compared to Accurel PP S6/2 membrane.

The formation of substantial amounts of deposits on the membrane surface was observed during the MD process, hence, the process efficiency was reduced by $20-40 \%$ during $150-200 \mathrm{~h}$ of process operation. A decline of efficiency was limited by the application of a periodical rinsing of the membranes. Besides the formation of organic deposits on the membrane surface, the membrane scaling was also observed. The deposit of precipitated salts contained mainly $\mathrm{CaCO}_{3}$, and it can be effectively removed by rinsing the MD membranes with a $5 \mathrm{wt} \% \mathrm{HCl}$ solution.

Acknowledgements The National Science Centre, Poland is acknowledged for the support of this work, grant number 2018/29/B/ ST8/00942.

\section{Compliance with ethical standards}

Conflict of interest The corresponding author states that there is no conflict of interest. 
Open Access This article is licensed under a Creative Commons Attribution 4.0 International License, which permits use, sharing, adaptation, distribution and reproduction in any medium or format, as long as you give appropriate credit to the original author(s) and the source, provide a link to the Creative Commons licence, and indicate if changes were made. The images or other third party material in this article are included in the article's Creative Commons licence, unless indicated otherwise in a credit line to the material. If material is not included in the article's Creative Commons licence and your intended use is not permitted by statutory regulation or exceeds the permitted use, you will need to obtain permission directly from the copyright holder. To view a copy of this licence, visit http://creativecommons.org/licenses/by/4.0/.

\section{References}

Beck R, Andreassen J-P (2010) The onset of spherulitic grow thin crystallization of calcium carbonate. J Cryst Growth 312:2226-2238. https://doi.org/10.1016/j.jcrysgro.2010.04.037

Chew NGP, Zhao S, Loh ChH, Permogorov N, Wang R (2017) Surfactant effects on water recovery from produced water via directcontact membrane distillation. J Membr Sci 528:126-134. https ://doi.org/10.1016/j.memsci.2017.01.024

Duong HC, Gray S, Duke M, Cath TY, Nghiem LD (2015) Scaling control during membrane distillation of coal seam gas reverse osmosis brine. J Membr Sci 493:673-682. https://doi.org/10.1016/j.memsc i. 2015.07 .038

Elfil H, Roques $\mathrm{H}$ (2004) Prediction of the limit of the metastable zone in the " $\mathrm{CaCO}_{3}-\mathrm{CO}_{2}-\mathrm{H}_{2} \mathrm{O}$ " system. AIChE J 50:1908-1916. https ://doi.org/10.1002/aic.10160

Eykens L, De Sitter K, Dotremont C, Pinoy L, Van der Bruggen B (2017) Membrane synthesis for membrane distillation: a review. Sep Purif Technol 182:36-51. https://doi.org/10.1016/j.seppu r.2017.03.035

Eykens L, De Sitter K, Dotremont C, Pinoy L, Van der Bruggen B (2018) Coating techniques for membrane distillation: an experimental assessment. Sep Purif Technol 193:38-48. https://doi. org/10.1016/j.seppur.2017.10.070

Gryta M (2017) The application of polypropylene membranes for production of fresh water from brines by membrane distillation. Chem Pap 71:775-784. https://doi.org/10.1007/s1169 6-016-0059-6

Gryta M (2018) The long-term studies of osmotic membranes distillation. Chem Pap 72:99-107

Gryta M, Karakulski K (1999) The application of membrane distillation for the concentration of oil-water emulsions. Desalination 121:23-29

Gryta M, Karakulski K, Morawski AW (2001) Purification of oily wastewater by hybrid UF/MD. Wat Res 35:3665-3669. https:// doi.org/10.1016/S0011-9164(99)00004-1

Guillén-Burrieza E, Blanco J, Zaragoza G, Alarcón DC, Palenzuela P, Ibarra M, Gernjak W (2011) Experimental analysis of an air gap membrane distillation solar desalination pilot system. J Membr Sci 379:386-396. https://doi.org/10.1016/j.memsci.2011.06.009

Guo F, Servi A, Liu A, Gleason KK, Rutledge GC (2015) Desalination by membrane distillation using electrospun polyamide fiber membranes with surface fluorination by chemical vapor deposition. ACS Appl Mater Interfaces 7:8225-8232. https://doi.org/10.1021/ acsami.5b01197

Hagedorn A, Fieg AG, Winter D, Koschikowski J, Mann T (2017) Methodical design and operation of membrane distillation plants for desalination. Chem Eng Res Des 125:265-281. https://doi. org/10.1016/j.cherd.2017.07.024

Hamzah N, Leo CP (2017) Membrane distillation of saline with phenolic compound using superhydrophobic PVDF membrane incorporated with $\mathrm{TiO}_{2}$ nanoparticles: separation, fouling and self-cleaning evaluation. Desalination 418:79-88. https://doi. org/10.1016/j.desal.2017.05.029

Hou D, Ding Ch, Li K, Lin D, Wang D, Wang J (2018) A novel duallayer composite membrane with underwater-superoleophobic/ hydrophobic asymmetric wettability for robust oil-fouling resistance in membrane distillation desalination. Desalination 428:240 249. https://doi.org/10.1016/j.desal.2017.11.039

Ji X, Curcio E, Al Obaidani S, Di Profio G, Fontananova E, Drioli E (2010) Membrane distillation-crystallization of seawater reverse osmosis brines. Sep Purif Technol 71:76-82. https://doi. org/10.1016/j.seppur.2009.11.004

Li X, Wang C, Yang Y, Wang X, Zhu M, Hsiao BS (2014) Dual-biomimetic superhydrophobic electrospun polystyrene nanofibrous membranes for membrane distillation. ACS Appl Mater Interfaces 6:2423-2430

Lin S, Nejati S, Boo C, Hu Y, Osuji CO, Elimelech M (2014) Omniphobic membrane for robust membrane distillation. Environ Sci Technol Lett 1:443-447. https://doi.org/10.1021/ez500267p

Lin P-J, Yang M-C, Li Y-L, Chen J-H (2015) Prevention of surfactant wetting with agarose hydrogel layer for direct contact membrane distillation used in dyeing wastewater treatment. J Memb Sci 475:511-520. https://doi.org/10.1016/j.memsci.2014.11.001

Lu D, Liu Q, Zhao Y, Liu H, Ma J (2018) Treatment and energy utilization of oily water via integrated ultrafiltration forward osmosis-membrane distillation (UF-FO-MD) system. J Membr Sci 548:275-287. https://doi.org/10.1016/j.memsci.2017.11.004

Macedonio F, Ali A, Poerio T, El-Sayed E, Drioli E, Abdel-Jawad M (2014) Direct contact membrane distillation for treatment of oilfield produced water. Sep Purif Technol 126:69-81. https://doi. org/10.1016/j.seppur.2014.02.004

McGaughey AL, Gustafson RD, Childress AE (2017) Effect of longterm operation on membrane surface characteristics and performance in membrane distillation. J Membr Sci 543:143-150. https ://doi.org/10.1016/j.memsci.2017.08.040

Mostafa MG, Zhu B, Cran M, Dow N, Milne N, Desai D, Duk M (2017) Membrane distillation of meat industry effluent with hydrophilic polyurethane coated polytetrafuoroethylene membranes. Membranes 7:55. https://doi.org/10.3390/membranes7 040055

Nieto DR, Santese F, Toth R, Posocco P, Pricl S, Fermeglia M (2012) Simple, fast, and accurate in silico estimations of contact angle, surface tension, and work of adhesion of water and oil nanodroplets on amorphous polypropylene surfaces. ACS Appl Mater Interfaces 4:2855-2859. https://doi.org/10.1021/am3004818

Rácz G, Kerker S, Schmitz O, Schnabel B, Kovács Z, Vatai G, Ebrahimi M, Czermak P (2015) Experimental determination of liquid entry pressure (LEP) in vacuum membrane distillation for oily wastewaters. Mem Wat Treatment 6:237-249. https://doi. org/10.12989/mwt.2015.6.3.237

Rezaei M, Warsinger DM, Lienhard VJH, Duke MC, Matsuura T, Samhaber WM (2018) Wetting phenomena in membrane distillation: mechanisms, reversal, and prevention. Wat Res 139:329-352. https://doi.org/10.1016/j.watres.2018.03.058

Rezaeia M, Warsinger DM, Lienhard VJH, Samhaber WM (2017) Wetting prevention in membrane distillation through superhydrophobicity and recharging an air layer on the membrane surface. J Membr Sci 530:42-52. https://doi.org/10.1016/j.memsc i.2017.02.013

Salmón IR, Luis P (2018) Membrane crystallization via membrane distillation. Chem Eng Process Process Intensification 123:258-271. https://doi.org/10.1016/j.cep.2017.11.017

Schwantes R, Cipollina A, Gross F, Koschikowski J, Pfeifle D, Rolletschek M, Subiela V (2013) Membrane distillation: solar and waste heat driven demonstration plants for desalination. Desalination 323:93-106. https://doi.org/10.1016/j.desal.2013.04.011 
Szcześ A (2009) Influence of the surfactant nature on the calcium carbonate synthesis in water-in-oil emulsion. J Cryst Growth 311:1129-1135. https://doi.org/10.1016/j.jcrysgro.2008.12.044

Tanudjaja HJ, Chew JW (2018) Assessment of oil fouling by oil-membrane interaction energy analysis. J Membr Sci 560:21-29. https ://doi.org/10.1016/j.memsci.2018.05.008

Tavakkoli S, Lokare OR, Vidic RD, Khanna V (2017) A techno-economic assessment of membrane distillation for treatment of Marcellus shale produced water. Desalination 416:24-34. https://doi. org/10.1016/j.desal.2017.04.014

Wang P, Chung TS (2015) Recent advances in membrane distillation processes: membrane development, configuration design and application exploring. J Membr Sci 474:39-56. https://doi. org/10.1016/j.memsci.2014.09.016
Winter D, Koschikowski J, Gross F, Maucher D, Düver D, Jositz M, Mann T, Hagedorn A (2017) Comparative analysis of fullscale membrane distillation contactors-methods and modules. J Membr Sci 524:758-771. https://doi.org/10.1016/j.memsc i.2016.11.080

Publisher's Note Springer Nature remains neutral with regard to jurisdictional claims in published maps and institutional affiliations. 